\title{
EL CORREDOR SECO CENTROAMERICANO EN PERSPECTIVA HISTÓRICA
}

\author{
THE CENTRAL AMERICAN DRY CORRIDOR \\ IN A HISTORICAL PERSPECTIVE
}

Ronald E. Díaz Bolaños

Recibido: 04/03/2019 - Aceptado: 22/07/2018

\begin{abstract}
Resumen
El artículo aborda, mediante una revisión bibliográfica, los procesos económicos y sociales desarrollados en el Corredor Seco Centroamericano, ubicado en la vertiente pacífica de América Central. Desde tiempos antiguos, este territorio ha sido habitado por poblaciones humanas que se adaptaron a sus condiciones climáticas particulares. Este contexto geográfico favoreció el proceso de Conquista y colonización europea que propició la ganadería y otras actividades productivas. A partir del siglo XIX, con el surgimiento de los Estados nacionales, esas tierras fueron incorporadas al modelo económico capitalista agroexportador que consolidó el desarrollo agropecuario. El objetivo de este trabajo es analizar los procesos socioeconómicos presentes en el CSC desde los inicios de la presencia humana hasta mediados del siglo XX.
\end{abstract}

Palabras clave: América Central, historia, clima, economía, sociedad.

\begin{abstract}
This article addresses through a literature review the economic and social processes developed in the Central American Dry Corridor located on the Pacific slope of Central America. Since ancient times, this territory has been inhabited by human populations that adapted to their particular climatic conditions. This geographic context favored the process of European conquest and colonization that led to livestock and other productive activities. From the 19th century, with the emergence of national states, these lands were incorporated into the capitalist agro-export economic model that consolidated agricultural development. The objective of this work is to analyze the socioeconomic processes present in the CADC from the beginning of the human presence until the middle of the 20th century.
\end{abstract}

Keywords: Central America, history, climate, economics, society. 


\section{Introducción}

Este trabajo ${ }^{1}$ tiene como objetivo evidenciar los principales procesos económicos y sociales que han tenido lugar en el Corredor Seco Centroamericano (CSC) desde una perspectiva histórica. De manera que constituye una síntesis de dichos procesos económicos y sociales, los cuales han tenido lugar en ese determinado espacio, el cual se encuentra constituido por las zonas del istmo ubicadas en torno a la costa del Pacífico; por sus condiciones físicas son más propensas a sufrir períodos de sequías y el prolongamiento de la estación seca. Estas tierras han sido habitadas muchos siglos antes de que tuviera lugar el proceso de Conquista y ocupación por parte de los conquistadores y colonizadores españoles. Tanto las poblaciones originarias como las que arribaron posteriormente a los territorios comprendidos por el CSC se han debido adaptar a las condiciones de un medio que posee un clima más seco que el ofrecido por la vertiente del Caribe.

A partir del siglo XVI, la implantación de la estructura colonial española sobre los pueblos originarios del istmo significó la introducción de nuevas actividades económicas que se adaptaron a las condiciones climáticas propias del CSC, entre estas, la ganadería extensiva, la cual a su vez coexistió con el cultivo del añil, la cochinilla y el maíz, que ya eran propios de la zona. Además, en este período se establecieron los principales asentamientos urbanos donde residió el poder político colonial, que en muchos casos se fundaron dentro de este espacio.

El surgimiento de los Estados nacionales centroamericanos en el siglo XIX favoreció el desarrollo de un modelo económico agroexportador que permitió a su vez el impulso de nuevos cultivos como el café, el cual ocupó parte de su espacio y coexistió con otras actividades económicas tradicionales hasta que terminó por desplazarlas; mientras que el algodón comenzó a tomar importancia como producto comercial hacia mediados del siglo XX.

Esta investigación se basa en una recopilación bibliográfica de datos referentes a procesos económicos y sociales que se han desarrollado en el CSC desde tiempos antiguos hasta mediados del siglo XX, los cuales fueron sistematizados a partir de la información relacionada con dichos ámbitos estudiados con anterioridad en obras referentes a la historia de los países centroamericanos, especialmente aquellos trabajos que ofrecen una visión de conjunto como la Historia General de Centroamérica y la Historia del Istmo Centroamericano. Luego fue complementado con información procedente de artículos académicos y libros relacionados con el desenvolvimiento histórico de las condiciones económicas y sociales en Centroamérica, tanto a nivel regional como nacional. La información perteneciente a Panamá, donde se encuentra el Arco Seco, se obtuvo de obras relacionadas con la historia de este país y de los procesos económicos y sociales que se han desarrollado en dicho espacio que, por sus condiciones climáticas, presenta similitudes con las del CSC. 
En términos cronológicos, este artículo comprende desde las primeras manifestaciones de presencia humana en tierras centroamericanas, unos 10000 años a. C., hasta mediados del siglo XX, cuando el modelo agroexportador comienza a entrar en crisis y es sustituido paulatinamente por el de sustitución de importaciones.

\section{Aspectos conceptuales}

América Central constituye un concepto de carácter geográfico, empleado para designar al conjunto de tierras que unen la América del Norte con la América del Sur, además, comprende desde el istmo de Tehuantepec (México), en su sección septentrional, hasta el valle del río Atrato (Colombia), en su punto meridional (Fonseca, 2013). Este territorio actúa como un puente que permite la unión de ambas masas continentales americanas y, al mismo tiempo, su condición ístmica separa las aguas del océano Pacífico de las del mar Caribe, lo cual ha facilitado el intercambio de flora, fauna y poblaciones humanas durante milenios. Lo anterior explica la existencia de una diversidad biológica y cultural que se distribuye a través de su variedad de relieves y climas. Al respecto, Robert Carmack apunta: "Pocos lugares en el mundo, de tamaño equivalente, varían tanto como la región centroamericana en la forma del terreno, el clima, la flora, la fauna, los suelos y la vegetación" (21); además del interés geoestratégico que este espacio presenta para las comunicaciones intercontinentales y transoceánicas, lo que ha condicionado el desarrollo de los países que se ubican en esta porción de la superficie terrestre (Granados).

A diferencia del concepto anterior, el de Centroamérica plantea un carácter histórico porque designa al territorio integrado por los cinco países que constituyeron el antiguo Reino de Guatemala durante la época colonial -Guatemala, Honduras, El Salvador, Nicaragua y Costa Rica- y que poco después de la proclamación de la independencia (1821) intentaron forjar una unidad política bajo el nombre de Provincias Unidas del Centro de América y, posteriormente, República Federal de Centroamérica (Fonseca, 2013). Panamá proclamó su independencia de Colombia en 1903 y ha aumentado sus vínculos con Centroamérica a raíz de los procesos de integración de las naciones ístmicas a partir de la segunda mitad del siglo XX y fue precisamente en este país donde se logró establecer la tan anhelada comunicación interoceánica con la que alguna vez soñaron las élites centroamericanas (Díaz, 2013).

La geografía centroamericana está conformada por dos vertientes, una pacífica y otra caribeña, divididas por un eje montañoso que atraviesa el istmo. Dentro de la primera se destaca un conjunto de zonas caracterizadas por la presencia de una estación seca definida, la cual en promedio tiene lugar entre los meses de noviembre y mayo. Las precipitaciones tienden a ser menores que en la costa del Caribe y por sus condiciones físicas son proclives a experimentar sequías (Fonseca, 2013). 
En la vertiente pacífica sobresale una llanura costera que posee las siguientes características (tanto físicas como sociales). Existencia de regiones planas ligeramente interrumpidas por la presencia de montañas próximas a la costa, en las cuales predomina el bosque tropical seco, con algunas transiciones al bosque tropical húmedo; este ha sido fuertemente intervenido gracias a la expansión de la ganadería extensiva y la agricultura de exportación, lo cual propició la disminución de la fauna y de las especies de árboles maderables para uso comercial. Esta planicie constituye un espacio de alta concentración poblacional, alberga un importante desarrollo vial y contiene suelos de gran fertilidad afectados por la constante aplicación de agroquímicos, en detrimento de los ecosistemas locales (Barillas).

Es en esta vertiente donde se ubica el CSC, espacio descrito de la siguiente manera:

Un grupo de ecosistemas que se combinan en la ecorregión del bosque tropical seco de Centroamérica, que inicia en Chiapas, México; y, en una franja, abarca las zonas bajas de la vertiente del Pacífico y gran parte de la región central premontana (0 a $800 \mathrm{msnm})$ de Guatemala, El Salvador, Honduras, Nicaragua y parte de Costa Rica (hasta Guanacaste); en Honduras, además, incluye fragmentos que se aproximan a la costa Caribe (Van der Zee, Van der Zee, Meyrat, Poveda y Picado 8).

Además del espacio anteriormente señalado, el CSC se extiende hacia algunas zonas del Pacífico Central y del sector occidental del Valle Central de Costa Rica como señalan Retana et al. (2012) y más recientemente Díaz y Mora (2017), así como el denominado Arco Seco de Panamá que comprende la mayor parte de los distritos que integran las provincias de Los Santos, Herrera y Coclé, además de algunos de Panamá Oeste e incluye gran parte de las zonas caracterizadas por una estación seca que supera los cuatro meses y una disminución en las precipitaciones. Su punto medular es la porción oriental de la Península de Azuero, donde existen planicies que constituyen una zona "casi seca por falta de lluvias; de ahí que ofrezca poca vegetación y en algunos casos ninguna" (Espino y Martínez 16). El Arco Seco de Panamá se define como una ecorregión caracterizada por:

Un clima de sabana tropical y un promedio anual de precipitación de 1,054 mm. En la época lluviosa, se muestran periodos de sequía hasta de 20 días. Los periodos de sequía más prolongados se han presentado coincidentemente con la aparición del fenómeno de El Niño (Castillo y Patiño 7).

Desde el punto de vista climático, el CSC:

Posee una marcada y prolongada época seca (verano) y durante la época de lluvias (invierno) existe un latente riesgo a las sequias recurrentes, que ocurren por una entrada tardía del invierno, una prolongación de la canícula o una suspensión prematura del invierno (González 9). 
De acuerdo con Mikkelsen, Sagua y Lima, el concepto de corredor se refiere a un espacio caracterizado por la presencia de un eje longitudinal en el cual convergen una serie de elementos físicos y sociales que permiten establecer conexiones entre sí. En el caso del CSC, este eje longitudinal lo constituye la llanura costera que discurre a través de la vertiente pacífica centroamericana, en la cual están presentes una serie de factores climáticos (existencia de una estación seca) y biogeográficos (bosque tropical seco y sabanas) que le confieren unidad a este territorio. No obstante, como lo advierten Retana et al.:

Aunque la idea de 'corredor' puede entenderse como una zona homogénea, extensa y continua, el área que se identifique puede ser segmentada y pertenecer a diferentes regímenes climáticos. Por tanto, la biodiversidad y el entorno asociado son variados, pudiendo albergar grupos poblacionales diversos en cuanto a sus medios de vida y su condición de vulnerabilidad social y económica (21-22). El CSC durante el período antiguo (10000 a. C.-1502 d. C.).

En una investigación reciente, Quesada et al. (2019) llegan a la conclusión que el CSC es un espacio caracterizado por su dinamismo debido a que su extensión varía según la cantidad de precipitaciones experimentada anualmente, por lo que se expande durante los años secos y se contrae en los años lluviosos.

\section{El CSC durante el período antiguo (10000 a. C.-1502 d. C.)}

El territorio que actualmente es América Central comenzó a ser habitado hace unos 10000 a. C. Estas primeras poblaciones experimentaron una serie de cambios a través del tiempo y pasaron de ser simples cazadores y recolectores para formar sociedades que empiezan a asentarse en el territorio y a desarrollar la agricultura. Algunas de estas llegaron a alcanzar un complejo desarrollo social y cultural, según el grado de adaptación que tuvieron con respecto al espacio que habitaron. Las tierras bajas del Pacífico, caracterizadas por su estación seca definida y la presencia de un bosque tropical seco alternado por sabanas, charrales espinosos y manglares (áreas costeras), fueron aprovechadas de la siguiente manera por sus habitantes:

Los recursos naturales de las tierras bajas del Pacifico proveían la mayoría de los productos exóticos que también se encontraban en las tierras bajas del norte [de América Central]. La sal era recolectada a lo largo de la costa, mientras que plumas brillantes y pues de ocelotes y otros felinos se obtenían en grandes cantidades. Había disponibilidad de maderas duras para la construcción y para la manufactura de canoas. De otros árboles se obtenía caucho, copal y tinte, mientras que de la corteza de la higuera se fabricaba papel y del árbol de bálsamo una medicina aromática. Existían muchas otras plantas de tintes en la zona, entre ellas el indigo [añil], el achiote y genipap. El tabaco (yat) fue cultivado en el área y manufacturado en $<<$ cigarros $>>$, mientras que la coca (yaat) fue cultivada en la costa pacífica de Nicaragua (Carmack 28-29). 
En la Figura 1 se representan los principales asentamientos humanos que surgieron en tiempos antiguos dentro del CSC.

Figura 1

ASENTAMIENTOS HUMANOS EN AMÉRICA CENTRAL RELACIONADOS CON EL CSC EN EL PERIODO ANTIGUO

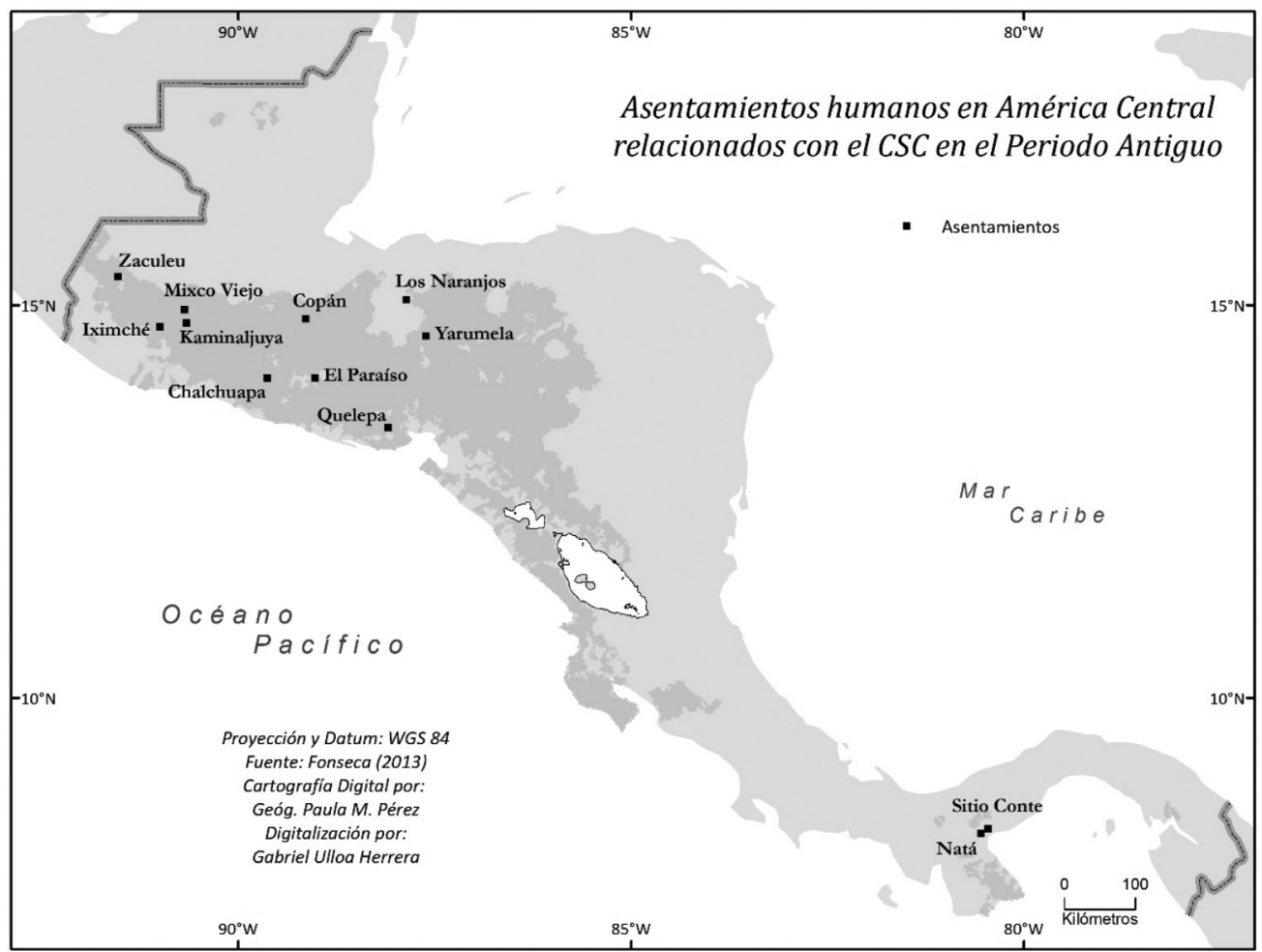

Fuente: Fonseca (2013).

Un ejemplo del alto grado de desarrollo cultural alcanzado por las poblaciones originarias es la civilización maya que ocupó la porción septentrional del istmo centroamericano, denominada Zona Norte o Zona Maya. Si bien la civilización maya alcanzó su apogeo en las tierras bajas situadas fuera del CSC, surgieron algunos asentamientos en la vertiente del Pacífico, entre estos, los de Chalchuapa (El Salvador), el cual se constituyó en un centro político y económico de gran importancia en los confines del mundo maya y pudo funcionar como el punto de avanzada más al sur de la red de intercambios de la cultura olmeca y Kaminaljuyú (Guatemala), que presenta una serie de construcciones públicas que pudieron tener un uso ceremonial (Rovira, 2000a; Fonseca, 2013). El cultivo del maíz se convirtió en uno de los productos fundamentales en la dieta de las poblaciones mayas, tanto dentro como fuera del CSC. 
El asentamiento de Copán (Honduras) fue una de las principales ciudades del período clásico de la civilización maya (600-1200 d. C.) y su zona circundante fue intensamente talada, lo cual pudo reflejar la presión demográfica existente sobre sus recursos forestales. En las postrimerías del período antiguo florecieron los asentamientos tardíos de Iximché, capital de los cakchiqueles; y Zaculeu, el principal centro de los mam y Mixco Viejo, todos situados en la actual Guatemala y que sucumbieron ante el dominio español durante la primera mitad del siglo XVI (Henderson). Cabe señalar que Neff, Bove y Genovez, basados en estudios arqueológicos, paleobotánicos y paleoclimatológicos, llegaron a la conclusión de que, en el período posclásico (900-1400 d. C.), la costa pacífica guatemalteca experimentó períodos de desocupación humana que podrían asociarse con temporadas de sequías, las cuales afectaron dicha zona del istmo centroamericano y vinculadas al fenómeno de El Niño.

Hacia el sureste de la Zona Maya se ubica la denominada Región Central, espacio donde se destacó la cultura lenca y la presencia de flujos migratorios a través de la llanura costera del Pacífico, conformado por poblaciones mesoamericanas que se instalaron en el oeste de Nicaragua y en la Península de Nicoya (nahuas y chorotegas) entre 800 y 1300. Estos pueblos construyeron una importante red comercial para el intercambio de alfarería, algodón, cacao, oro, plumas y manufacturas hechas en piedra; la presencia de estos pueblos en la costa pacífica nicaragüense y nicoyana provocó la reacción de matagalpas y huetares por la defensa de sus territorios. La población de esta región domesticó árboles de aguacate, ciruelo, coyol, mamey, marañón y zapote y cultivaron algodón, añil, ayote, cacao, coca, frijoles, maíz y tabaco (Rovira, 2000b, Ibarra; Fonseca, 2013).

En esta zona se desarrollaron algunos asentamientos importantes, como los de El Paraíso (El Salvador), Los Naranjos y Yarumela (Honduras), cuyas edificaciones revelan la influencia de los patrones arquitectónicos mesoamericanos; mientras que el sitio Quelepa (El Salvador) constituyó un centro regional de intercambios comerciales y políticos con el mundo maya. En la Zona Sur del istmo, propiamente en la Península de Azuero (Panamá), se desarrollaron algunos sitios como los de Sarigua y Sitio Conte, los cuales presentan una reducida complejidad social, debido a la ausencia de una estratificación socioeconómica claramente definida y donde el hallazgo de instrumentos de piedra evidenció el desarrollo agrícola alcanzado por sus habitantes (Rovira, 2000b; Castillo y Patiño).

En términos ambientales, la construcción de asentamientos urbanos en la época anterior a la Conquista europea, principalmente en las tierras habitadas por los pueblos mayas, trajo consigo la roturación de bosques y se experimentaron procesos de erosión y cambios en algunos cursos fluviales (Fonseca, 2005).

\section{El CSC en el período colonial (1502-1821)}

La exploración de las costas centroamericanas por parte de los españoles se remonta al cuarto viaje de Cristóbal Colón (¿1451?-1506) en 1502; no obstante, el proceso 
de conquista de las tierras del interior del istmo se desarrolló entre las décadas de 1520 y 1560, por lo cual los conquistadores españoles debieron someter a diferentes poblaciones indígenas distribuidas a través del territorio ístmico. En particular en la vertiente pacífica, primero bajo la esclavitud y posteriormente por medio del sistema de encomiendas, el cual significó la asignación de determinado número de indígenas a un encomendero, quien, gracias a los tributos, tenía acceso a alimentos, bienes y otros productos elaborados por los encomendados (Kramer, Lovell y Lutz; Ibarra).

Los mismos conquistadores, al momento de ocupar el actual territorio centroamericano, presenciaron las diferencias existentes entre las condiciones físicas de ambas vertientes y la estructura socioeconómica de sus poblaciones originarias:

En el momento de la invasión española, las sociedades indígenas que poblaban Centroamérica no eran en modo alguno homogéneas; sin embargo, es posible distinguir dos grandes áreas de influencia cultural: una de origen mesoamericano, donde la población era más densa y la agricultura presentaba un mayor grado de desarrollo, se extendía desde Guatemala y El Salvador, abarcando el lado del Pacífico de Honduras y Nicaragua, y el Pacífico Norte de Costa Rica; otra, de origen suramericano, se extendía a lo largo del lado del Atlántico, y se caracterizaba por un grado menor de desarrollo de la agricultura, con patrones de poblamiento disperso (Fonseca, 1994, 96).

Durante el proceso de conquista de las tierras del istmo centroamericano, la costa pacífica tendió a presentar condiciones climáticas más propicias que la vertiente del Caribe, donde las lluvias son abundantes. La estación seca es prácticamente inexistente y los exuberantes bosques tropicales húmedos cubrían sus suelos (Solórzano, 2002). En cambio, en la vertiente pacífica, debido a la existencia de una estación seca que coincide con el invierno boreal, se facilitaron los viajes de exploración como el de Gil González Dávila (1480-1526) en 1522, quien penetró en el cacicazgo huetar de Pacaca en el Valle Central de Costa Rica (Molina, 1993; Molina, 2005).

Este viaje de exploración fue posible gracias a la fundación de la Ciudad de Panamá en 1519, ya que permitió la realización de expediciones de conquista por la costa pacífica de la Centroamérica meridional, las cuales llevaron al establecimiento de los asentamientos de Villa Bruselas (actual Costa Rica), León y Granada (Nicaragua) a cargo de Francisco Hernández de Córdoba (¿1475?-1526) en 1524; mientras que un año antes, Pedro de Alvarado (1485-1541), partiendo de la Ciudad de México, se dirigió hacia la costa pacífica de la Centroamérica septentrional. Lo anterior culminó con el sometimiento de varios reinos indígenas -no sin antes enfrentar una férrea resistencia- y la fundación de las ciudades de Santiago de los Caballeros de Guatemala (1524) y San Salvador (1525) en sus sitios originales (Fonseca, 2013).

La ciudad de Santiago de los Caballeros de Guatemala fue el principal centro político establecido por los españoles en Centroamérica y sería la sede de la Capitanía 
General de Guatemala. Fue trasladada -por un terremoto- de su tercer asentamiento (actualmente Antigua Guatemala) en la década de 1770, al de Nueva Guatemala de la Asunción (actual Ciudad de Guatemala) y ambas ciudades se ubicaron dentro del CSC (Guevara-Murua, Williams, Hendy e Imbach). En la Figura 2 se observan los principales asentamientos hispánicos que se constituyeron en importantes centros de comercio durante el período colonial y la producción agropecuaria ligada al CSC.

Figura 2

ACTIVIDADES PRODUCTIVAS EN AMÉRICA CENTRAL EN EL PERIODO COLONIAL (1502-1821)

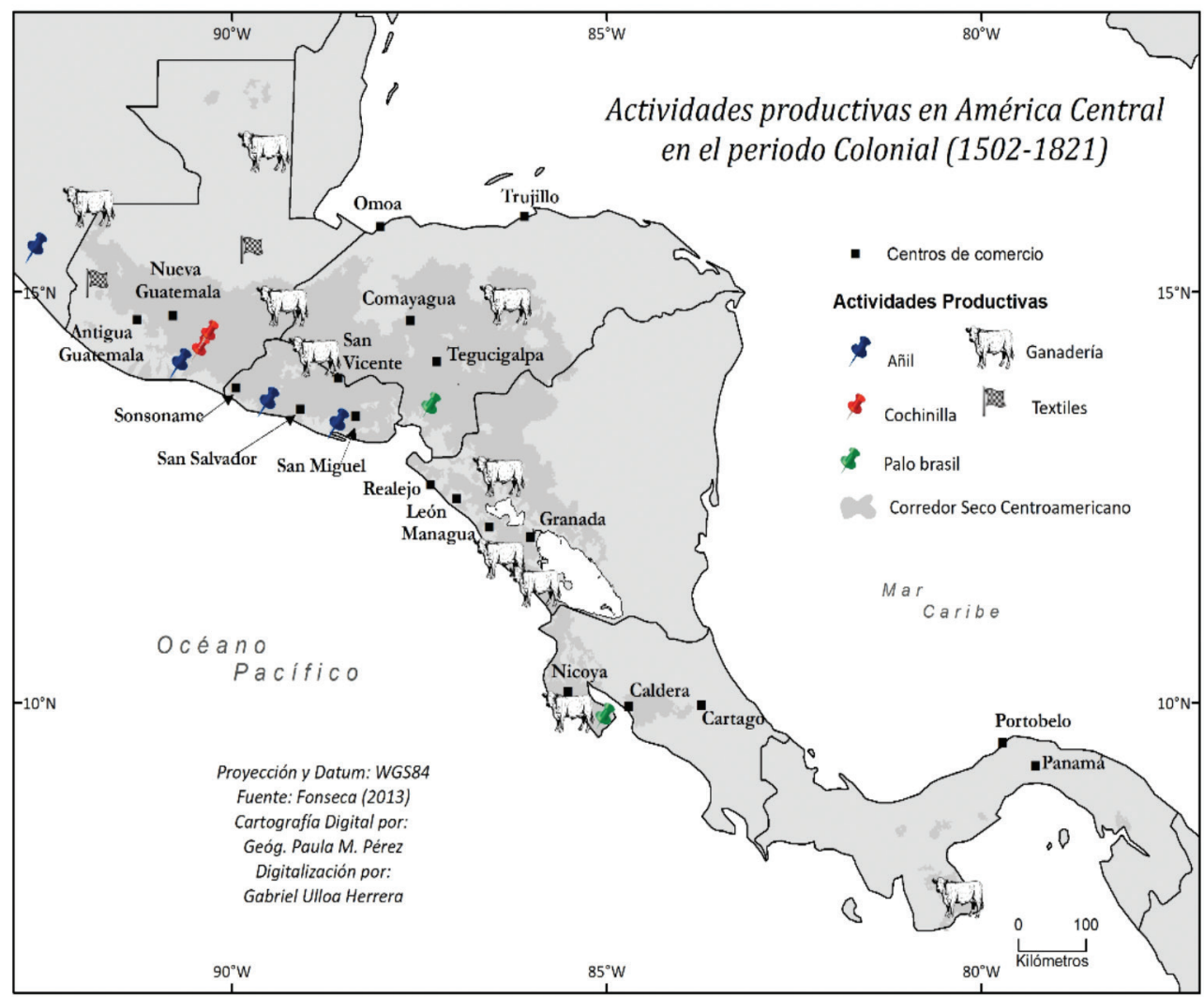

Fuente: Hall y Pérez y Fonseca (2013).

De acuerdo con Kramer, Lovell y Lutz: "las mejores condiciones, para el establecimiento de la encomienda, se dieron en los altiplanos y en la vertiente del Pacífico, donde se concentraban los pequeños estados y cacicazgos, entidades políticas con tradición de sistemas tributarios y de trabajo forzoso" (58), por lo cual un entorno climático más favorable les permitió a los conquistadores implantar sus estructuras 
económicas, sociales y políticas sobre las desarrolladas por los pueblos originarios del Pacífico, a diferencia de los del Caribe, quienes habitaban tierras del bosque tropical húmedo y cuya estructura socioeconómica tenía un carácter tribal, lo cual dificultó su sometimiento a la autoridad colonial española.

El diplomático e historiador estadounidense Dana Gardner Munro (1892-1990) afirmó que el proceso de colonización española en las planicies de la vertiente del Pacífico de Nicaragua, entre la costa y los lagos, fue favorecido por el clima cálido, lo cual les permitió a los europeos controlar una abundante mano de obra procedente de las poblaciones originarias de la zona (Munro). A pesar de la fertilidad de los suelos y la relativa disponibilidad de agua, esta última se veía condicionada durante la estación seca, debido a la escasez de ríos y manantiales en las zonas montañosas ubicadas entre la costa pacífica y la cuenca lacustre, por eso sus habitantes tenían problemas para abastecerse de dicho líquido; no obstante, la concentración de la población en este espacio se mantendrá a través de los próximos siglos, debido a sus condiciones geográficas relativamente favorables. En el caso hondureño, la ocupación del territorio comenzó en la costa caribeña y continuó hacia el interior, donde se explotaron yacimientos de plata y se fundó Santa María de Comayagua (1537) (Lindo, 1994; Fonseca, 2013).

Las Leyes Nuevas introducidas a partir de 1542 en las tierras conquistadas de América Central aseguraron el sistema de tributos que las autoridades impusieron a la declinante población indígena, el cual incluyó la producción de ágave (henequén), algodón, bálsamo, cacao, chiles picantes, gallinas de Castilla, pescado, sal y trigo en las tierras de la vertiente pacífica centroamericana, desde Guatemala hasta Nicaragua, además de la fabricación de objetos de cerámica, petates, prendas de vestir y toldillos (Hall y Pérez).

Las empresas de conquista del interior del actual territorio costarricense, como la emprendida por Juan de Cavallón (1524-1565) en 1560, aprovecharon las condiciones climáticas más favorables presentes en la costa pacífica. Lo anterior les permitió introducirse en dicho espacio y fundar un asentamiento como el Castillo de Garcimuñoz; a diferencia de su compañero Fray Juan de Estrada Rávago (¿1500-1570?), quien intentó penetrar infructuosamente en el mismo territorio a través de las húmedas llanuras del Caribe (Molina, 1993).

Para la Corona española, las tierras que actualmente constituyen América Central cumplían con un papel estratégico, al ubicarse en el punto limítrofe entre los territorios virreinales de Nueva España y el Perú. De acuerdo con Stephen Webre:

El istmo representaba el punto más estrecho del continente que guardaba el acceso al Mar del Sur [Océano Pacífico]. La vecina provincia de Panamá como ruta de tránsito para las ricas remesas de plata peruana significó que las colonias centroamericanas fueran también vulnerables al ataque de los enemigos de España. La respuesta adecuada a tal amenaza exigía la movilización de recursos humanos y materiales en una sociedad relativamente pobre, así como la ocupación 
efectiva del territorio istmeño, cosa que sólo logró parcialmente, durante la época colonial. Al concluir la Conquista a mediados del siglo XVI, la extensión territorial bajo control colonial no era considerable. Por lo general, los españoles solamente ocuparon aquellas regiones donde existía cierta densidad de población indígena y bienes que permitieran el enriquecimiento. Esto significó una concentración de actividades en el altiplano y en la vertiente del Pacífico, lugares donde se producían cosechas para la exportación, como sucedió con el cacao y el añil (181).

Durante el siglo XVIII, la población en América Central tendió a aumentar (especialmente la mestiza), si bien las zonas habitadas y las cultivadas fueron pequeñas, incluso, era usual que las cosechas se vieran afectadas por fenómenos naturales (enfermedades de las plantas, erupciones volcánicas, inundaciones, plagas de langostas y, desde luego, sequías). Aun así, la escasa pero creciente población y el aumento paulatino de las tierras cultivadas evitaron el desarrollo de hambrunas y, tanto en las comunidades indígenas como en pequeñas propiedades y en las haciendas, se produjeron cultivos de subsistencia, especialmente maíz y frijoles. La producción de algodón, frijoles, maíz y trigo tendió a concentrarse en la vertiente pacífica y en zonas comprendidas dentro del CSC, principalmente en Guatemala y El Salvador (Hall y Pérez).

Con la implantación de estructuras económicas españolas sobre los pueblos indígenas en la vertiente pacífica centroamericana, se introdujo el ganado vacuno, en especial en las zonas secas, donde se roturaron los bosques para formar pastizales para las haciendas, como sucedió en el istmo de Rivas (Nicaragua) y en la actual provincia de Guanacaste (Costa Rica). La cría de ganado vacuno sirvió para satisfacer las necesidades de alimentación de las poblaciones centroamericanas, además de la extracción de cebo y cuero; mientras que el ganado equino y mular se dedicó principalmente para el transporte. Era una actividad extensiva donde el ganado solía pastar libremente, por lo cual muchas veces perjudicó las siembras de las tierras comunales de los pueblos de indios (Fonseca, 2013).

La ganadería propició un cambio en las actividades económicas de las poblaciones indígenas sometidas al dominio de la Corona española:

Aunque las sociedades indigenas desconocian la ganadería, y a pesar de los frecuentes daños causados por los ganados en las sementeras, en un buen número de pueblos se fundaron cofradias, cuya principal riqueza era el ganado. Parte de la tierra comunal podía ser destinada a pastos, especialmente en las zonas costeras del Pacífico (Fonseca, 1994, 112).

Estas cofradías eran organizaciones de fieles católicos reunidas en torno a una devoción religiosa en particular y podían sostenerse económicamente gracias a la producción ganadera (Velázquez).

En el caso guanacasteco, el desarrollo ganadero que empezó a gestarse a principios del siglo XVII se vio beneficiado porque: 
las planicies regadas por el rí Tempisque presentaban mejores condiciones para la cría del ganado. Los elementos que determinaron la ubicación de los hatos ganaderos fueron cuatro: la disponibilidad de espacio, la existencia de ríos, el acceso a las costas y el crecimiento natural de los pastos (Díaz y Salazar 136-137).

Aunado a lo anterior, Díaz y Salazar indican:

El relieve del Valle del Tempisque facilitó la práctica de la ganadería extensiva. Las grandes planicies deshabitadas permitieron el desarrollo de una producción caracterizada por su bajo nivel tecnológico: la mayoría de los hatos pastaban libremente en estado semisalvaje, alimentándose de la vegetación de la sabana (hierbas y gramineas). Las llanuras aluviales permitieron el desarrollo de una agricultura de subsistencia (maíz, plátanos, yuca, frijoles), destinada a satisfacer las necesidades de quienes se dedicaban al cuido del ganado. Las laderas de la Cordillera de Guanacaste aseguraban pastos verdes todo el año que se explotaban durante la época seca; estos eran alimento imprescindible para las vacas destinadas a la producción de queso (<<queseras $>$ ) Por último, la cuenca del Tempisque tenía fácil acceso a la costa y eso aseguraba la provisión de sal para alimentar al ganado y de agua salada que se utilizaba para eliminar a las garrapatas (137).

La producción de ganado vacuno fue precedida por la cría de mulas que se produjo en la vertiente pacífica entre Choluteca (Honduras) y el territorio comprendido por la ciudad de Esparza y los valles de Abangares, Bagaces, Cañas y Chomes (Costa Rica), las cuales fueron destinadas al comercio transístmico de Panamá y eran enviadas tanto por vía marítima a dicha ciudad, a través del puerto de Caldera (Costa Rica), como por vía terrestre, a partir de la apertura del Camino de Mulas (1601). En toda la zona mencionada, la actividad ganadera estimuló la colonización gracias a la conformación de un sistema de haciendas especializado en la cría y engorde de semovientes (Solórzano, 1994; Quirós).

A partir del ganado vacuno se extraía el cuero y el sebo, empleado a su vez para la fabricación de barniz utilizado en las embarcaciones y de candelas para uso cotidiano. No obstante, la actividad ganadera en la Península de Nicoya se vio perjudicada por las incursiones de piratas que se introducían en las haciendas para el abastecimiento de carne (incluso Nicoya fue saqueada en 1738). Por lo tanto se produjo un declive que estuvo asociado también a la explotación desmedida de los semovientes y al aumento de la adquisición de productos agropecuarios procedentes de Ecuador y Perú en los mercados panameños, de modo que las haciendas ganaderas ubicadas en el sector norte del Partido de Nicoya prosperaron ante la decadencia de las situadas en la zona peninsular (Fonseca, 1994; Díaz y Salazar). El ligamen entre las actividades productivas de las haciendas guanacastecas con las condiciones climáticas del territorio podría sinterizarse de la siguiente manera: 
En la estación lluviosa, se atendian las labores agrícolas; se daba mantenimiento al casco (infraestructura física de la hacienda); y se producían quesos destinados al mercado nicaragüense.

Durante la estación seca, el ganado diseminado por la hacienda era recogido y llevado a los corrales para marcarlo (<<rodeo >> o fierra) y tener control de su aumento... Las faenas de la fierra incluían la selección del hato que sería enviado a Guatemala y la eliminación de parásitos (garrapatas y tórsalos) (Díaz y Salazar 138).

Los ganaderos de Costa Rica, Honduras y Nicaragua, al finalizar el siglo XVIII, enfrentaron a los comerciantes de Guatemala por sus planes de controlar el comercio de ganado mediante la prohibición de la venta de semovientes realizada fuera de la Feria de Chalchuapa (El Salvador), lo cual llevó a las autoridades locales a plantear peticiones a la Corona y posteriormente a las Cortes de Cádiz, para separarse de Guatemala. Este sentimiento pudo haber influido en los movimientos independentistas que brotaron en las provincias centroamericanas durante la segunda década del siglo XIX (Díaz, 2013).

En el caso de Panamá, el desarrollo ganadero se experimentó en las zonas del interior del territorio ístmico, entre estas, la Península de Azuero, donde esta actividad económica fue introducida a inicios del siglo XVI y cuyo sistema productivo experimentó pocos cambios hasta el siglo $\mathrm{XX}$, a diferencia de la región comprendida entre la Ciudad de Panamá y Portobelo, dedicadas al comercio transístmico. En la Península de Azuero, durante el período colonial, se establecieron pequeños propietarios de diversa procedencia étnica (españoles, mestizos, indígenas y africanos libertos) dedicados a trabajar la tierra. Incluso, varios comerciantes que se asentaron en la región del tránsito comercial adquirieron propiedades en el interior, debido a la decadencia de las ferias de Portobelo (siglo XVIII), dedicándose a la agricultura y la ganadería; sin embargo, la escasa producción de carne, arroz, caña de azúcar y maíz generaban pocos ingresos y apenas abastecían los mercados locales (Espino y Martínez). Durante el período colonial, se establecieron algunas poblaciones en el área comprendida por el Arco Seco, entre ellas La Villa de Los Santos, Las Tablas, Natá de los Caballeros y Parita (Castillo y Patiño).

En el territorio salvadoreño comienza a desarrollarse un ciclo económico basado en la producción del añil, llamado también xiquilite, planta de la cual se extrae un colorante azul que fue exportado fuera del istmo en las postrimerías del siglo XVIII e inicios del siglo XIX; esto le otorgó un dinamismo económico a la Alcaldía Mayor de San Salvador (Fernández). Las tierras salvadoreñas fueron el espacio ideal para el desarrollo de la producción de añil, debido a que este cultivo prospera en terrenos bajos de clima caliente y húmedo, con suelos arcillosos y arenosos, por lo que San Vicente llegó a convertirse en un centro productor de primer orden, seguido de San Salvador y San Miguel (Palma). 
La producción del añil se basó principalmente en técnicas de recolección y procesamiento ancestrales que posteriormente fueron sustituidas por el sistema de obrajes, introducido por los españoles. Los terrenos plantados de añil se preparaban durante la estación seca (diciembre a marzo) y la siembra tenía lugar antes del inicio de la época de lluvias (abril), en los siguientes meses se le aplicaban una serie de cuidados, hasta que finalmente se extraía la semilla en octubre. A diferencia de otras zonas productoras en el continente americano, como las Antillas Menores, Carolina del Sur y Haití, la producción del añil centroamericano se basaba en un único corte, no solamente por razones climáticas, sino también por las dificultades generadas por la disponibilidad de mano de obra y de tierras, así como del acceso a los mercados externos (Fernández).

El desarrollo del cultivo del añil en la Alcaldía Mayor de San Salvador en la segunda mitad del siglo XVIII incentivó la producción ganadera en Nicaragua y consolidó el sistema de haciendas en el Valle del Tempisque y en la sección oriental del Golfo de Nicoya (Costa Rica), para abastecer de productos derivados del ganado vacuno a la zona añilera; por lo cual la producción de este colorante natural constituyó la base de un espacio económico que integró una sección considerable de la vertiente pacífica centroamericana (Pérez).

Los valles de Amatitlán y Chimaltenango (Guatemala) fueron otro importante centro de producción ganadera, lo mismo que la zona costera de Acasaguastlán, Chiquimula, Escuintla y Guazacapán, cuyas haciendas importaban ganado procedente de Honduras, Nicaragua, incluso, de Nicoya, para engordarlo y comercializarlo en los mercados guatemaltecos y salvadoreños. En cuanto a Choluteca (Honduras), el ganado mular tendió a predominar frente al vacuno; mientras que el añil incentivó la producción de granos y textiles en la zona de Santiago de Guatemala y en el altiplano occidental guatemalteco (Palma; Solórzano, 1994; Fonseca, 2013; Díaz y Salazar).

En la costa del Pacífico se desarrolló una importante actividad comercial en torno a los principales puertos de Sonsonate (El Salvador), de donde se enviaba el añil a los obrajes de Lima y Quito en América del Sur; El Realejo (Nicaragua) de donde se exportaba alquitrán y brea para los astilleros y la industria vitivinícola del Perú; y finalmente Caldera (Costa Rica), de donde se exportaban los productos procedentes del Valle Central costarricense hacia Panamá (Palma). Además, debido al estado de la red de caminos en el interior del istmo, el transporte de mercancías tenía lugar durante la estación seca, entre noviembre y abril, cuando estos se encontraban en mejores condiciones (Fernández). En algunas zonas próximas a la costa, como ocurrió en Guatemala, se establecieron asentamientos por parte de mulatos libres que aprovecharon su relativo aislamiento con respecto a los principales centros urbanos y desarrollaron un modo de vida al margen de la estructura político-administrativo colonial (Lokken). 
A lo largo de la costa pacífica de América Central, la producción de sal fue una actividad económica bastante apreciada desde tiempos antiguos, debido a su uso para la preservación de alimentos, el empleo como moneda y sus propiedades medicinales y hasta en los rituales religiosos, que luego los españoles extendieron para la alimentación del ganado, el curtido de pieles y el procesamiento de la plata en las minas de Honduras. La extracción de sal se realizaba por medio de técnicas sencillas de cocimiento aplicadas en esteros, lagunas litorales y playas salitrosas durante la estación seca y debido a las dificultades que implicaba su transporte fue objeto de enfrentamientos entre pueblos originarios en tiempos antiguos, aunque bajo el dominio de la Corona española varios pueblos de indios debieron aportar tributos de sal a las autoridades coloniales (Andrews; Ibarra).

En algunas zonas costeras se produjo también la extracción de perlas como actividad económica, entre ellas la isla de Chira, las costas occidentales del Golfo de Nicoya y algunas playas de la península homónima (Costa Rica), donde las poblaciones locales extrajeron perlas de la especie Pinctada mazatlanica, labor que se prolongaría hasta inicios del siglo XX (Payne).

La actividad cacaotera floreció también en la costa pacífica guatemalteca, salvadoreña y nicaragüense, asociada a la producción del añil, y adquirió tal importancia que permitió el surgimiento del asentamiento de Rivas (Nicaragua) y el desplazamiento de la actividad ganadera hacia las haciendas del Pacífico norte costarricense, rubro que decayó con la importación de cacao procedente de Guayaquil (Ecuador). También hubo explotaciones de palo brasil en la zona comprendida entre el Golfo de Fonseca y la Península de Nicoya, de cuya madera se extrae un tinte rojo que también fue objeto de exportación hacia América del Sur y más tarde Europa (Quirós; Herrera; Solórzano, 2001).

Finalmente, los movimientos antiespañolistas y antifiscales que precedieron al proceso de independencia tuvieron lugar entre 1811 y 1814, en las ciudades de San Salvador, Granada y León, ubicadas en el CSC. No obstante, el descontento hacia los monopolios impuestos al comercio centroamericano por el Estado español y sus autoridades no provocó un movimiento campesino como el que se experimentó en ese momento en México (Fonseca, 2013).

En síntesis, a nivel ambiental el desarrollo de la ganadería extensiva afectó los ecosistemas de las tierras ubicadas en le vertiente pacífica de América Central; mientras que la extracción de leña en los bosques, situados en la proximidad de las ciudades y villas, provocó el aumento de la deforestación. La introducción de cultivos de interés comercial, como la caña de azúcar y el trigo en terrenos con una topografía caracterizada por la presencia de laderas, incentivaron procesos de erosión, especialmente con el uso del arado. Incluso, las inundaciones que experimentó la ciudad de Santiago de los Caballeros de Guatemala a finales del siglo XVII llevó a las autoridades coloniales a prohibir el cultivo de los cerros vecinos (Fonseca, 2005). 


\section{El CSC desde los inicios del período republicano hasta la crisis del modelo agroexportador (1821-1950)}

La ruptura del orden colonial español tuvo lugar en Centroamérica a inicios del decenio de 1820, los nacientes Estados centroamericanos se unieron para conformar una República federal (1824-1838), la cual, tras convertirse en un proyecto político inviable, favoreció el surgimiento de Estados nacionales, cuyas principales autoridades políticas se instalaron en la vertiente del Pacífico, desde donde dirigieron los procesos de construcción de la identidad nacional de los pueblos que gobernaban. En algunos países fue más temprano, como en el caso de Costa Rica, y en otros más tardío, por ejemplo, en Honduras (Díaz, 2013). En el caso de Nicaragua, las pugnas entre las élites locales de León y Granada, ambas ubicadas en el oeste del país, se tradujeron en enfrentamientos armados que llevaron a la intervención de las fuerzas filibusteras de William Walker (1824-1860) en suelo nicaragüense en la década de 1850 y controlaron la Vía del Tránsito que agilizaba las comunicaciones entre ambas costas norteamericanas, mediante un sistema de navegación establecido entre el río San Juan de Nicaragua, el Lago Cocibolca y el istmo de Rivas.

A lo largo del siglo XIX, los nacientes Estados ístmicos que surgieron tras la disolución de la República Federal Centroamericana comienzan a moldear sus propias estructuras económicas basadas en la experiencia colonial. De esta forma, Guatemala y El Salvador continuaron produciendo la grana o cochinilla y el añil, respectivamente, hasta que fueron desplazados por el café, producto que ya había sido cultivado y exportado con éxito por Costa Rica al mercado mundial.

La grana era un colorante rojo que se extraía de un insecto conocido popularmente como cochinilla, el cual se alimenta de una variedad de nopal que crece en el área conformada por las localidades de Amatitlán, Antigua Guatemala, Petapa y Villanueva (Guatemala) y en menor medida en Santa Ana (El Salvador). Debido a la demanda que tuvo la cochinilla para los mercados europeos, este producto se convirtió en el principal rubro de exportaciones para Guatemala, pese al impacto de las plagas y las irregularidades en el ciclo de lluvias que destruían las plantaciones de nopal (Lindo, 2000).

El desarrollo de la caficultura en las tierras medias y altas de la vertiente pacífica centroamericana implicó una transformación del paisaje de dicha zona, porque los cafetos fueron cultivados en áreas extensas tradicionalmente destinadas a la producción agrícola de subsistencia y a la ganadería extensiva, por lo cual supuso la apertura de nuevas tierras para la colonización en los que este cultivo de exportación coexistió con sembradíos de maíz, frijoles y otros productos para abastecer el mercado interno de los países del istmo (Fonseca, 2013).

Este producto configuró un espacio económico fragmentado en Centroamérica, porque las zonas cafetaleras se ubicaron en la vertiente pacífica de cada uno de los países, 
lo que no favoreció la integración de los territorios centroamericanos ya que cada país se constituía en un productor independiente y se empeñaba en colocar su producto aisladamente en el mercado internacional por medio del mejoramiento de sus vías de comunicación e infraestructura portuaria (Pérez).

El café fue para los políticos liberales centroamericanos un cultivo que promovía la modernización económica debido a que su expansión propiciaba la privatización de tierras comunales -principalmente en manos de poblaciones indígenas- necesarias para el desarrollo de un producto de exportación que requería la inversión de capital y la aplicación de técnicas adecuadas que superaban las tradicionales ligadas a la producción del maíz y al pastoreo (Gudmunson).

Además de los terrenos dedicados a la caficultura, otras zonas fueron incorporadas a la dinámica económica de los nacientes estados nacionales centroamericanos, en particular aquellas tierras realengas que teóricamente pertenecientes a la Corona española pasaron, tras los procesos de independencia, a conceptualizarse como tierras baldías, entre ellas las planicies costeras del Pacífico guatemalteco y salvadoreño, que se especializaron en el cultivo de caña de azúcar y algodón, además de los pastizales empleados para la alimentación del ganado en las nuevas haciendas establecidas por colonos (Hall y Pérez).

Esta etapa de la vida política y económica de los países centroamericanos coincide con una creciente presencia de científicos, exploradores y viajeros estadounidenses y europeos por el istmo, quienes harán importantes descripciones de sus experiencias donde detallarán aspectos sobre su geografía física y social. Entre esos visitantes se encuentra el diplomático estadounidense John Lloyd Stephens (1805-1852), quien recorrió la vertiente pacífica centroamericana y experimentó los rigores de la estación seca en El Salvador, Nicaragua y en el departamento de Guanacaste (Costa Rica), donde describió la disminución de los cauces de ríos importantes y la ausencia del agua en los arroyos, además de la sequedad de los suelos y las nubes de polvo levantadas por el viento (Díaz, 2015). Stephens afirmó que el clima de la zona que rodea al lago Xolotlán, o de Managua, "era un perpetuo verano", el cual dentro de su visión de progreso decimonónico podría ser contraproducente para el rendimiento de colonos anglosajones que quisieran residir en la zona (17).

La ganadería continuó desarrollándose como actividad económica a lo largo de la costa pacífica centroamericana. Los principales centros de producción Choluteca y Nacaome (Honduras) eran Segovia, Matagalpa y Chontales (Nicaragua) y en la provincia de Guanacaste y las llanuras al este del Golfo de Nicoya (Costa Rica). El ganado se comercializó en El Salvador y Guatemala, aunque parte de la producción ganadera hondureña se exportó a la colonia española de Cuba (Gudmunson; Quirós; Fonseca, 2013). En Panamá, la ganadería extensiva prosperó en el Arco Seco; mientras que la expansión de la caña de azúcar permitió roturar los bosques y favorecer una fragmentación de la tierra entre pequeñas y grandes propiedades (Castillo y Patiño). 
A partir de la década de 1870 el modelo agroexportador tiende a consolidarse en América Central, de la mano de las reformas liberales que tienen lugar en varios de los países del istmo, los cuales trajeron sus repercusiones políticas, sociales y económicas, entre estas, la construcción de ferrocarriles, la privatización de mayor cantidad de tierras, con el fin de cultivar los productos de exportación, y la introducción de la plantación bananera explotada bajo un sistema de enclave en la vertiente caribeña centroamericana (Acuña).

No obstante, los países centroamericanos debieron vencer una dificultad que hizo que el comercio exterior se viera limitado desde el período colonial:

Los principales mercados internacionales se encontraban en Europa, al otro lado del Atlántico, mientras que las tierras más fértiles y la mayor parte de la población de Centroamérica se encontraban en los valles cercanos a la costa del Pacífico, separadas de los puertos del Atlántico por cadenas de montañas (Lindo, 2000, 334).

Esta situación había sido observada a inicios del siglo XIX por Alexander von Humboldt (1769-1859), quien advirtió que el territorio de Centroamérica, "al igual que Quito, Perú y Chile, es más adecuado para la comunicación con Asia oriental que con el viejo continente" y la presencia de "la larga fila montañosa que se extiende de sudeste a noroeste por todo el territorio y que empalma con los Andes colombianos de Veragua con los Andes mexicanos de Chiapa y Oaxaca" (Humboldt 91). Lo anterior no constituía un obstáculo insalvable debido a la existencia de ríos navegables y valles transversales donde podrían trazarse carreteras que comunicaran ambas vertientes. De ahí que la construcción de vías férreas se volvió en un imperativo para los gobiernos centroamericanos.

El café continuó cultivándose con éxito en las tierras medias de la vertiente pacífica centroamericana en cuatro de los cinco países: Costa Rica, El Salvador, Guatemala y, en menor medida, Nicaragua; para ello se aprovecharon tierras fértiles de origen volcánico cuyas condiciones climáticas permitían diferenciar claramente la presencia de dos estaciones. Estas tierras concentraban una mayor densidad demográfica que en las zonas bañadas por el Mar Caribe y experimentaron una constante transformación del paisaje rural mediante la creciente expansión de las fincas cafetaleras donde este cultivo coexistió con los potreros y las milpas, remanentes de actividades agropecuarias tradicionales (Samper). En el caso de Honduras, el café tuvo una importancia menor como actividad económica debido al peso que tenían la producción bananera en su costa caribeña, así como la actividad minera y la ganadería en el interior del país.

La recolección del café tenía lugar en la estación seca, la cual podría variar de octubre a enero y de noviembre a febrero, según la zona donde se cultivaba. Lo anterior facilitaba también el transporte del grano hacia los beneficios (agroindustrias especializadas en su procesamiento) y los puertos, donde era embarcado para exportarlos a 
los mercados europeos y estadounidense. En los beneficios ubicados en zonas donde solía escasear el agua, como en el Oriente salvadoreño y en el Pacífico centro-sur nicaragüense, el grano era procesado a través de la vía seca, lo cual producía un café de menor calidad y que se vendía a un precio menor en el mercado internacional.

El desarrollo de la caficultura en Centroamérica, además de su importante papel en la vinculación del mercado mundial, incentivó el surgimiento de mercados internos en cada uno de los países. La vertiente del Pacífico se caracterizó también por ser el espacio para el cultivo de la caña de azúcar, el maíz, el tabaco, los frijoles, las hortalizas y los tubérculos, que se destinaban al consumo interno, pero que no llegaron a satisfacer completamente su abastecimiento, debido a la importación de granos básicos - una parte significativa de ellos producidos en Nicaragua- hecha por Costa Rica y El Salvador, mientras que la ganadería, conservaba su carácter extensivo y abarcaba gran cantidad de tierras que superaban los terrenos cultivados (Samper).

Al iniciar el siglo XX, el bicultivismo caracterizó a la economía centroamericana porque el café y el banano se consolidaron como los principales productos de exportación. No obstante, los países centroamericanos se vieron afectados por las fluctuaciones de sus precios en el mercado internacional, en particular durante las coyunturas críticas provocadas por el impacto de la Primera Guerra Mundial (1914-1918), la gran depresión económica de la década de 1930 y la Segunda Guerra Mundial (19391945). Lo anterior evidencia la vulnerabilidad de las economías agroexportadoras, las cuales a su vez trajeron repercusiones sociales y políticas en el istmo, entre las que destacan activos movimientos sociales y el ascenso y caída de regímenes dictatoriales (Bulmer-Thomas).

En la Figura 3 se observa cómo la actividad cafetalera se desarrolla en secciones a través de las tierras medias del istmo centroamericano, tanto dentro como en la periferia del CSC; mientras que el algodón, cuya expansión tiene lugar a mediados del siglo XX, se cultiva principalmente en las llanuras costeras de la vertiente pacífica del istmo. 
Figura 3

ACTIVIDADES PRODUCTIVAS EN AMÉRICA CENTRAL 1900-1960

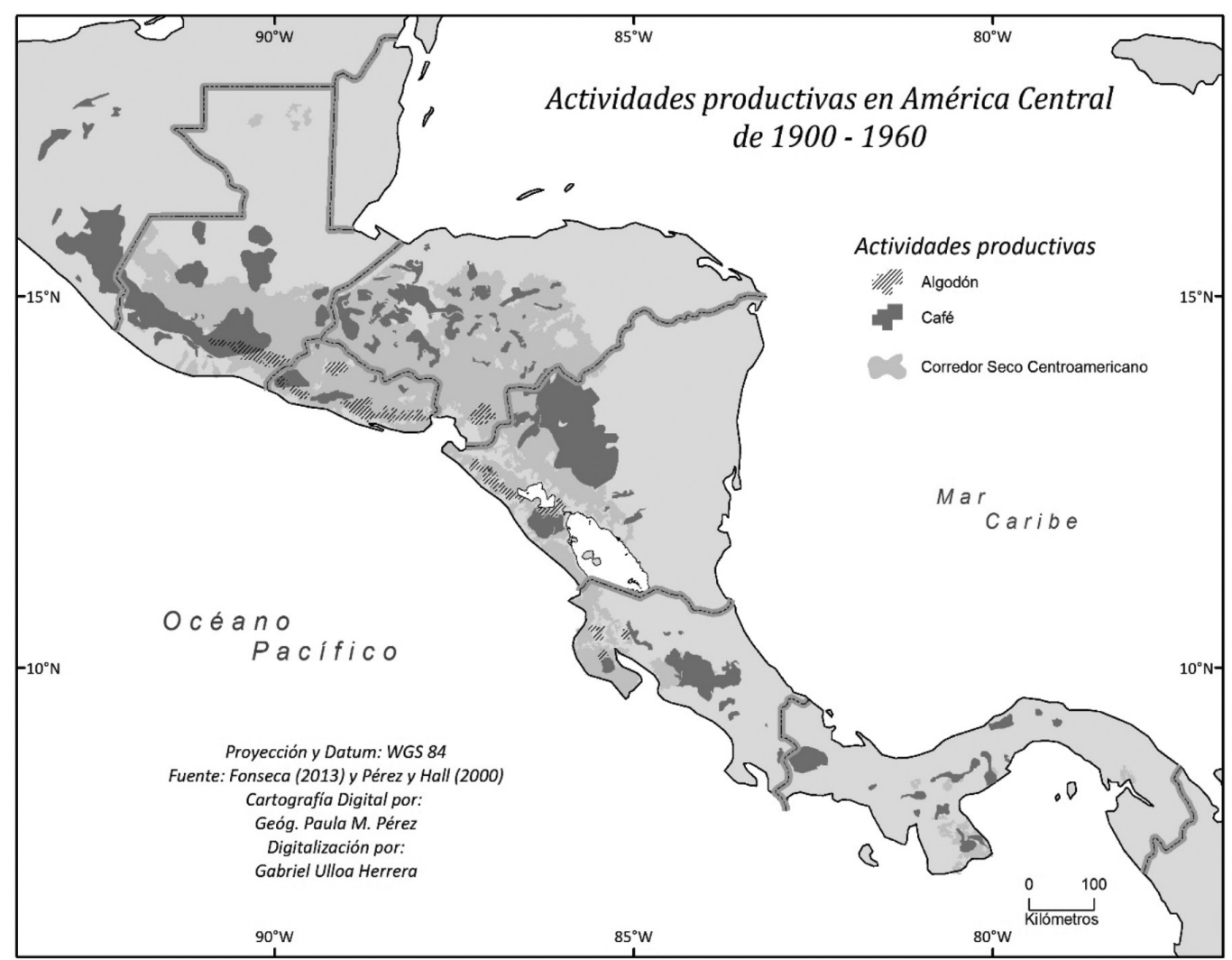

Fuente: Hall y Pérez y Fonseca (2013).

Debido al impacto de las crisis internacionales, los países centroamericanos impulsaron intentos de diversificar sus economías a mediados del siglo XX: Guatemala se especializa en la producción de zacate de limón para la extracción de aceite; Nicaragua se orienta hacia el cultivo de algodón y del ajonjolí; mientras que se da un repunte de la ganadería en Costa Rica y la producción de cereales para el consumo interno se generalizó en todo el istmo (Bulmer-Thomas; Viales).

El algodón se cultivó principalmente en las planicies costeras del Pacífico en Nicaragua, Guatemala y El Salvador, donde las condiciones climáticas hacían propicia su producción, en terrenos planos que podían ser trabajados mediante el uso de maquinaria que hizo posible el aumento del rendimiento de esta planta textil: “En 1950, el algodón era ya el principal cultivo y el producto agrícola de exportación más importante de Nicaragua, país que concentraba el 53 \% del área 
sembrada en la región y el $71 \%$ de la producción centroamericana" (Fonseca, 2013, 215-216).

La política de diversificación agrícola tiene lugar en un contexto donde los países del istmo se ven afectados por las crisis que han provocado el descenso de los precios del café y del banano en el mercado mundial. No obstante, una vez finalizado el segundo conflicto bélico internacional, los gobiernos centroamericanos reorientaron sus políticas económicas para reactivar la caficultura y las plantaciones bananeras, por lo cual los intentos de diversificación agrícola tienden a estancarse (Viales).

Mientras tanto en Panamá, la ganadería extensiva también continuó siendo la principal actividad en las zonas rurales -entre ellas las del Arco Seco- al iniciar el primer cuarto de siglo de su vida como país independiente, rubro que se vio favorecido por la existencia de tierras donde los semovientes pastaban libremente ("ganado en soltura"); no obstante, el impacto que tuvo la Guerra de los Mil Días (1899-1902) en la estructura agraria panameña provocó la pérdida de más de la mitad del hato ganadero. La población campesina se volvió escasa y dispersa, además sufría por la inestabilidad en la posesión de la tierra y en las décadas que siguieron al conflicto armado. El ganado tendió a recuperarse y, a partir del decenio de 1930, los productores pecuarios obtuvieron créditos para invertirlos en la ganadería, aspecto que se vio beneficiado por el aumento de las vías de comunicación y por la tecnificación experimentada por el agro panameño (Ardito-Barletta; Castillo y Patiño).

No obstante, el proceso de construcción del Canal de Panamá y la apertura de esta vía interoceánica (1914) promovieron un proceso migratorio procedente del Arco Seco hacia la capital del país y su periferia; mientras que la construcción de ingenios azucareros y el cultivo del tomate llegaron a complementarse con la actividad ganadera:

Los agricultores de la región sobre todo en los minifundios evolucionaron de una economía de auto consumo y una ganadería extensiva en época lluviosa a colonos en la producción de caña y tomate. Igualmente lo hará la mano de obra que pasa de campesino en la estación lluviosa a obrero-jornalero en el corte de caña y la cosecha de tomate, en la estación seca (Castillo y Patiño 27).

En cuanto a la actividad perlífera que se desarrollaba en las zonas costeras, Payne argumenta que la extinción de la especie Pinctada mazatlanica en las costas del Golfo de Nicoya se debió a la sobreexplotación de los bancos de ostras, el incremento de la población humana en el litoral, la presión sobre la tierra y su recurso hídrico.

Finalmente, la diversificación económica de América Central proseguirá en las décadas de 1950 y 1960, debido al creciente agotamiento del modelo agroexportador y se experimentará un incipiente desarrollo industrial basado en el modelo de sustitución de importaciones en el contexto del Mercado Común Centroamericano (MCCA). 
Las exportaciones de ganado fueron favorecidas por la expansión de tierras dedicadas a la ganadería, incluso fuera de la vertiente pacífica, además del aumento de la demanda de carne en el mercado estadounidense y del consumo interno en los países productores sudamericanos (Argentina, Uruguay y Brasil) (Viales).

En términos ambientales, la expansión de la caficultura trajo consigo una mayor extensión de la frontera agrícola y por ende, la fundación de nuevos asentamientos humanos y la apertura de fincas cafetaleras, propiedades dedicadas a la producción de granos para el consumo interno y haciendas ganaderas, además de la construcción de caminos y ferrocarriles, en detrimento de los bosques que eran talados y las maderas consumidas por el fuego provocado por los colonos (Fonseca, 2005).

\section{Conclusiones}

El CSC constituye un espacio geográfico que discurre a través de la vertiente pacífica centroamericana y trasciende las fronteras de los Estados nacionales del istmo, en el cual ha sucedido, a lo largo del tiempo, una serie de procesos de índole económica, social y política, los cuales han marcado profundamente las condiciones de vida de los pueblos de América Central. Si bien existen factores de índole biogeográfico que le confieren unidad, también se ha caracterizado por la diversidad de procesos físicos, económicos y sociales que tienen lugar en el territorio que lo conforma.

El CSC ha sido desde tiempos antiguos el hogar de diversas poblaciones humanas, las cuales debieron adaptarse a las condiciones climáticas propias de zonas donde la estación seca suele ser prolongada y, por tanto, más propensas a las sequías que las situadas en la vertiente caribeña del istmo centroamericano. Esto reviste capital importancia porque de acuerdo con Héctor Pérez: "la vida humana en el istmo se ha desenvuelto de preferencia en las laderas y valles cultivables próximos al litoral pacífi-

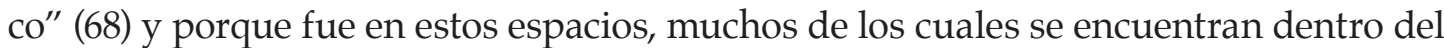
CSC, donde se conglomeraron las poblaciones humanas que fueron la base de las sociedades centroamericanas durante el período colonial y se constituyeron en naciones en las décadas que siguieron a los procesos de independencia.

Este territorio se ha caracterizado a través del tiempo por ser un espacio dinámico, en el cual esas poblaciones han interactuado y se han generado procesos económicos y sociales que tienen sus repercusiones en el presente, dentro de las cuales se pueden citar la concentración demográfica de una parte significativa de la población centroamericana, el surgimiento de importantes asentamientos humanos que han albergado a las autoridades civiles, una constante producción agrícola -empezando por la producción de añil en el período colonial y continuado por la agroindustria del café y algodón en los siglos XIX y XX-que históricamente ha sido el principal motor de la economía regional y un área propicia para la actividad ganadera desde el siglo XVI. No obstante, el análisis de las fuentes consultadas evidencia también las limitaciones 
generadas por la disminución del agua en los períodos secos más críticos que condicionaban el desarrollo de las poblaciones humanas y sus actividades económicas.

Mediante la investigación histórica es factible reconocer el desenvolvimiento de los procesos económicos y sociales que han tenido lugar en la vertiente pacífica centroamericana, especialmente en el CSC, pero se requieren de más estudios que permitan analizar desde una perspectiva histórica el impacto de los períodos de sequía, ligados a fenómenos locales o planetarios como El Niño-Oscilación del Sur (ENOS) en el desarrollo de las actividades productivas y en los contextos sociales en dicho espacio, así como la incidencia que ha tenido en ellos el cambio y la variabilidad climática a través de los diferentes períodos históricos, además de las repercusiones que tienen en el presente.

Por último, la realización de trabajos de historia local o regional con perspectiva ambiental permitiría generar mayores conocimientos sobre el impacto de los procesos económicos y sociales en el espacio comprendido por el CSC, debido a que la información disponible es bastante general y se refiere principalmente a la construcción de los antiguos asentamientos urbanos mayas, a la expansión de la ganadería durante el período colonial y de la caficultura en los siglos XIX y XX, por lo cual nuevas investigaciones podrían establecer comparaciones sobre la incidencia de las actividades humanas en las tierras comprendidas por este espacio en América Central.

\section{Nota}

1 Este artículo se produjo en el marco del Programa Estudios Sociales de la Ciencia, la Técnica y el Medio Ambiente (PESCTMA, VI-805-A4-906) y del Proyecto “Procesos Hidroclimatológicos en el Corredor Seco Centroamericano" (VI-805-B6-143) del MICITT-CONICIT y del Proyecto "Funding proposal for the advancing development and climate change resilience in the Central American Dry Corridor: translating science into policy in Guanacaste, Costa Rica, and interdisciplinary, international collaboration" (VI-805-B7-286) de UCREA ejecutados por el Centro de Investigaciones Geofísicas (CIGEFI) de la Universidad de Costa Rica. El autor agradece a la geógrafa Paula Marcela Pérez Briceño por su aporte en la elaboración de los mapas incluidos en el presente trabajo, a Gabriel Madriz-Sojo en la revisión del texto y a Edgardo Gallo Guzmán, Valeria Mora López y Arnaldo Rivera Loría por la búsqueda de fuentes bibliográficas y la cooperación brindada durante el proceso de investigación.

\section{Bibliografía}

Acuña, V. Los cambios políticos y sociales (1870-1930). Historia del istmo centroamericano. Tomo II. San José: Coordinadora Educativa y Cultural Centroamericana, 2000. 309-328.

Andrews, A. Las salinas de El Salvador: bosquejo histórico, etnográfico y arqueológico. Mesoamérica, 21(1991): 71-93.

Ardito-Barletta, N. La economía de Panamá en el siglo XX. Centenario de la República de Panamá: Historia económica e institucional y la ruta hacia la prosperidad. Comp. Ernesto Ayala y Roberto Artavia. San José, Costa Rica: EUNED, 2005. 1-32.

Barillas, E. El espacio y los seres humanos. Historia del istmo centroamericano. Tomo I. San José: Coordinadora Educativa y Cultural Centroamericana, 2000. 20-57. 
Bulmer-Thomas, V. La crisis de la economía de agroexportación (1930-1945). Historia General de Centroamérica. Tomo IV. Las repúblicas agroexportadoras (1870-1945). Ed. Víctor H. Acuña. San José: FLACSO, Programa Costa Rica, 1994. 325-397.

Carmarck, R. M. Introducción: Centroamérica aborigen en su contexto histórico y geográfico. Historia General de Centroamérica. Tomo I Historia Antigua. Ed. Robert M. Carmack. San José: FLACSO, Programa Costa Rica, 1994. 15-59.

Castillo, J. y Patiño, A. Diagnóstico y propuesta de desarrollo sostenible del Arco Seco de Panamá, 2012. Panamá: Universidad de Panamá, 2014.

Díaz, D. La construcción de las naciones centroamericanas, 1821-1954. América. La consolidación de las naciones. Ed. María Cristina Mineiro Scatamacchia y Francisco Enríquez Solano. Madrid: Instituto Panamericano de Geografía e Historia, Instituto Geográfico Nacional, Gobierno de España, Ministerio de Fomento, 2013. 64-97.

Díaz, R. La imagen del ambiente centroamericano en las obras de dos diplomáticos estadounidenses: John Lloyd Stephens y Dana Gardner Munro (1839-1918). Ciencia y ambiente: XVII Jornadas de Historia del Pensamiento Científico Argentino, Actas. Comp. Celina Lértora. Buenos Aires: FEPAI, 2015. 55-80.

Díaz, R. y Mora, L. La conservación de los bosques tropicales en el cantón de Mora, Costa Rica (1915-2017). Las disciplinas ambientales y sus problemas: fortalezas y debilidades: Proyecto EcoEpisteme. Coord. Celina Lértora. Buenos Aires: FEPAI, 2017. 197-224.

Díaz, R. y Salazar, Y. Historia de Costa Rica para el Turismo. San José: EUNED, 2017.

Fernández, J. A. Pintando el mundo de azul: el auge añilero y el mercado centroamericano, 17501810. San Salvador: Dirección de Publicaciones e Impresos, Consejo Nacional para la Cultura y el Arte, 2003.

Fonseca, E. Centroamérica. Su historia. San José: EUNED, 2013.

Fonseca, E. Economía y sociedad en Centroamérica (1540-1680). Historia General de Centroamérica. Tomo II. El régimen colonial (1524-1750). Ed. Julio C. Pinto. San José: FLACSO, Programa Costa Rica, 1994. 95-150.

Fonseca, E. Historia y ambiente en Centroamérica. GEO Centroamérica. Perspectivas del medio ambiente 2004. México: PNUMA y CCAD, 2005. 11-29.

González, A. Marco Estratégico Regional para la Gestión de Riesgos Climáticos en el Sector Agrícola del Corredor Seco Centroamericano. Tegucigalpa: FAO, 2012.

Granados, C. Hacia una definición de Centroamérica. El peso de los factores geopolíticos. Anuario de Estudios Centroamericanos, 11(1), 1985: 59-78.

Gudmunson, L. Sociedad y política (1840-1871). Historia General de Centroamérica. Tomo III. De la Ilustración al liberalismo (1750-1870). Ed. Héctor Pérez. San José: FLACSO, Programa Costa Rica, 1994. 203-256.

Guevara-Murua, Á., Williams, C. A., Hendy, E. J. y Imbach, P. 300 years of hydrological records and societal responses to droughts and floods on the Pacific coast of Central America. Climate of the Past, 14(2018): 175-191. DOI: doi.org/10.5194/cp-14-175-2018

Hall, C. y Pérez, H. Historical Atlas of Central America. Norman: University of Oklahoma Press, 2003.

Henderson, J. El mundo maya. Historia General de Centroamérica. Tomo I Historia Antigua. Ed. Robert M. Carmack. San José: FLACSO, Programa Costa Rica, 1994. 61-133.

Herrera, M. Á. Gentes de la mar. Marinos y comerciantes en el Pacífico Central mesoamericano, 1830-1860. Revista de Historia, 43(2001): 213-264.

Humboldt, A. Zentralamerika = Centroamérica. San José: EUCR, 2011. 
Ibarra, E. Pueblos que capturan. Esclavitud indígena al sur de América central del siglo XVI al XIX. San José: EUCR, 2012.

Kramer, W., Lovell, G. W. y Lutz, Christopher H. La conquista española de Centroamérica". Historia General de Centroamérica. Tomo II. El régimen colonial (1524-1750). Ed. Julio C. Pinto. San José: FLACSO, Programa Costa Rica, 1994. 21-93.

Lindo, H. Economía y sociedad (1810-1870). Historia General de Centroamérica. Tomo III. De la Ilustración al liberalismo (1750-1870). Ed. Héctor Pérez. San José: FLACSO, Programa Costa Rica, 1994. 141-201.

Lindo, H. La economía centroamericana (1821-1930). Historia del istmo centroamericano. Tomo II. San José: Coordinadora Educativa y Cultural Centroamericana, 2000. 331-354.

Lokken, P. Génesis de una comunidad afro-indígena en Guatemala: La Villa de San Diego De La Gomera en el siglo XVII. Mesoamérica, 50(2008): 37-65.

Mikkelsen, C. A., Sagua, M. y Lima, L. El concepto corredor como aporte a la comprensión del territorio. Geografia em questão, 7(1), 2014: 203-222.

Molina, C. Garcimuñoz. La ciudad que nunca murió. Los primeros cien días de Costa Rica. San José: EUNED, 1993.

Molina, C. Y las mulas no durmieron... Los arrieros en Costa Rica. Siglos XVI al XIX. San José: EUNED, 2005.

Munro, D. Las cinco repúblicas de Centroamérica. Desarrollo político y económico y relaciones con Estados Unidos. San José: EUCR y Plumsock Mesoamerican Studies, 2003.

Neff, H., Bove, F. J. y Genovez, J. V. El clima y la naturaleza de la ocupación del Postclásico en la Costa Sur de Guatemala. Ed. Juan Pedro Laporte, Bárbara Arroyo y Héctor Mejía. XIX Simposio de Investigaciones Arqueológicas en Guatemala, 2005. Guatemala: Museo Nacional de Arqueología y Etnología, 2006, 149-155. Recuperado de http://www.asociacion tikal.com/wp-content/uploads/2017/01/14_-_Neff_et_al.05_-_Digital.pdf

Palma, G. Economía y sociedad en Centroamérica (1680-1750). Historia General de Centroamérica. Tomo II. El régimen colonial (1524-1750). Ed. Julio C. Pinto. San José: FLACSO, Programa Costa Rica, 1994. 222-306.

Payne, E. La explotación perlífera en Centro y Suramérica: Una lectura desde la historia ambiental. Poder, economía y relaciones sociales en el reino de Guatemala. Coord. Carmela Velásquez y Elizet Payne. San José: EUCR, 2014, 49-71.

Pérez, H. Transformaciones del espacio centroamericano. Para una historia de América. Volumen II. Los nudos I. Coord. Marcello Carmagnani, Alicia Hernández y Romano Ruggiero. México: El Colegio de México - Fondo de Cultura Económica, 1999: 55-93.

Quesada, L., Calvo, O., Hidalgo, H., Pérez, P. y Alfaro, E. Dynamical delimitation of the Central American Dry Corridor (CADC) using drought indices and aridity values. Progress in Physical Geography: Earth and Environment 43(5), 2019: 627-642, DOI: doi. org $/ 10.1177 / 0309133319860224$

Quirós, C. La sociedad dominante y la economía cacaotera de Rivas, factores determinantes para el surgimiento de la 'hacienda de campo' en el Pacífico Norte costarricense: primera mitad del siglo XVIII. Anuario de Estudios Centroamericanos 25(2), 1999: 49-71.

Retana, J., Alvarado, L., Araya, C., Sanabria, N., Solano, J., Solera, M. y Alfaro, M. Caracterización del corredor seco en Costa Rica. Tópicos Meteorológicos y Oceanográficos, 11(1), 2012: 18-29. 
Rovira, B. Antiguas civilizaciones de la Zona Norte. Historia del istmo centroamericano. Tomo I. San José: Coordinadora Educativa y Cultural Centroamericana, 2000. 79-99.

Rovira, B. Sociedades antiguas de la Zona Central y Sur. Historia del istmo centroamericano. Tomo I. San José: Coordinadora Educativa y Cultural Centroamericana, 2000. 101-118.

Samper, M. Café, trabajo y sociedad en Centroamérica, (1870-1930): Una historia común y divergente. Historia General de Centroamérica. Tomo IV. Las repúblicas agroexportadoras (1870-1945). Ed. Víctor H. Acuña. San José: FLACSO, Programa Costa Rica, 1994. $11-110$.

Solórzano, J. C. Descubrimiento y conquista de Costa Rica 1502-1575. Costa Rica, estado, economía, sociedad y cultura desde las sociedades autóctonas hasta 1914. Comp. Ana M. Botey. San José: EUCR, 2002. 67-114.

Solórzano, J. C. Las relaciones comerciales de Costa Rica en el Pacífico (1575-1821). Revista de Historia, 43(2001): 93-142.

Solórzano, J. C. Los años finales de la dominación española (1750-1821). Historia General de Centroamérica. Tomo III. De la Ilustración al liberalismo (1750-1870). Ed. Héctor Pérez. San José: FLACSO, Programa Costa Rica, 1994. 13-71.

Stephens, J. L. Incidentes de viaje de Centroamérica, Chiapas y Yucatán. Tomo II. San José: EDUCA, 1971.

Van der Zee, A., Van der Zee, J., Meyrat, A., Poveda, C. y Picado, L. Estudio de caracterización del Corredor Seco Centroamericano. (Países CA-4). Tomo I. Tegucigalpa: FAO, 2012.

Velázquez, C. Diccionario de términos coloniales. San José: EUCR - Asociación Pro Historia Centroamericana, 2005.

Viales, R. Centroamérica en la globalización contemporánea. Cambio económico y persistencia de la pobreza (1980-2008). Historia de la Cultura. David Díaz, Ronny Viales y Juan J. Marín. San José: EUNED, 2012. 261-283.

Webre, S. Poder e ideología: la consolidación del sistema colonial (1542-1700). Historia General de Centroamérica. Tomo II. El régimen colonial (1524-1750). Ed. Julio C. Pinto. San José: FLACSO, Programa Costa Rica, 1994. 151-218.

Ronald E. Díaz Bolaños. Costarricense, obtuvo su Maestría en Historia por la Universidad de Costa Rica. Se desempeña como docente de la Escuela de Estudios Generales e investigador del Centro de Investigaciones Geofísicas de la Universidad de Costa Rica y tutor de la Cátedra de Historia de la Universidad Estatal a Distancia. Es autor y coautor de diversas publicaciones relacionadas con la Historia Social de la Ciencia, Historia Ambiental, Historia del Clima, Historia Eclesial, Historia Local e Historia del Deporte y entre sus obras más recientes se encuentran Historia de Costa Rica para el Turismo (2017), escrita en coautoría con Yery Javier Salazar Alfaro y "El desarrollo científico y tecnológico en la Unión Soviética (1917-1991). Una sinopsis" en la Revista Estudios (2018).

Contacto: ronald.diaz@ucr.ac.cr

ORCID: 0000-0003-2860-6744 